\section{Applying Civic Engagement to Emergency management: Developing the Vision and Design for Improved Governance Resilience to Emergencies}

\author{
Efrat Mishor, Eran Vigoda-Gadot and Shlomo Mizrahi \\ University of Haifa, Israel
}

\begin{abstract}
Civic engagement (CE) is a powerful part of social, personal, and political life (Bala, 2014). It has a potential to make significant impact on the making and implementing of public policy in various fields of government action (Park \& Kim, 2019). Thus, scholars have concluded that the behaviors and perceptions associated with CE have major implications for citizenship, democracy, and public management (Checkoway \& Aldana, 2013). A major factor related with $\mathrm{CE}$ is citizens' behavioral desire to improve the development of communities and their longrange wellbeing (Zukin, 2006). However, CE is usually examined in peaceful times and much less in turbulent times of crisis, emergencies, and disasters. This study focuses on CE in times of the COVID-19 pandemic. A theoretical model is developed targeting several questions: What is the uniqueness of $\mathrm{CE}$ during emergencies and what variables may explain it beyond what is already known in the literature? Do emergencies affect the nature of $\mathrm{CE}$ as well as other citizens' perceptions about and behaviors toward government and the community? We focus on the relationships between risk awareness, cost-benefit calculations, interpersonal trust, and trust in government and suggest a longitudinal design among Israeli citizens that may help answering these questions.
\end{abstract}

Keywords: Citizenry; Public policy; Political Science; Risk; Risk management 